\title{
A vibrational spectroscopic study of the borate mineral takedaite $\mathrm{Ca}_{3}\left(\mathrm{BO}_{3}\right)_{2}$
}

\author{
Ray L. Frost ${ }^{\mathrm{a}, *}$, Andrés López ${ }^{\mathrm{a}}$, Yunfei Xi ${ }^{\mathrm{a}}$, Leonardo M. Graça ${ }^{\mathrm{b}}$, Ricardo Scholz ${ }^{\mathrm{b}}$ \\ ${ }^{a}$ School of Chemistry, Physics and Mechanical Engineering, Science and Engineering Faculty, Queensland University of Technology, GPO Box 2434, Brisbane, Queensland 4001, Australia \\ ${ }^{\mathrm{b}}$ Geology Department, School of Mines, Federal University of Ouro Preto, Campus Morro do Cruzeiro, Ouro Preto, MG 35400-00, Brazil
}

\section{H I G H L I G H T S}

- We have studied the mineral takedaite $\mathrm{Ca}_{3}\left(\mathrm{BO}_{3}\right)_{2}$.

- A borate mineral of calcium using SEM with EDX and vibrational spectroscopy.

- Chemical analysis shows a homogeneous phase, composed by Ca.

- No Raman bands were observed in the $\mathrm{OH}$ stretching region.

- A very intense Raman band at $1087 \mathrm{~cm}^{-1}$ is assigned to the $\mathrm{BO}$ stretching vibration of $\mathrm{BO}_{3}$ units.

\section{A R T I C L E I N F O}

\section{Article history:}

Received 20 February 2014

Received in revised form 28 May 2014

Accepted 3 June 2014

Available online 12 June 2014

\section{Keywords:}

Takedaite

Borate

Calcium

Raman spectroscopy

Infrared spectroscopy

\section{G R A P H I C A L A B S T R A C T}

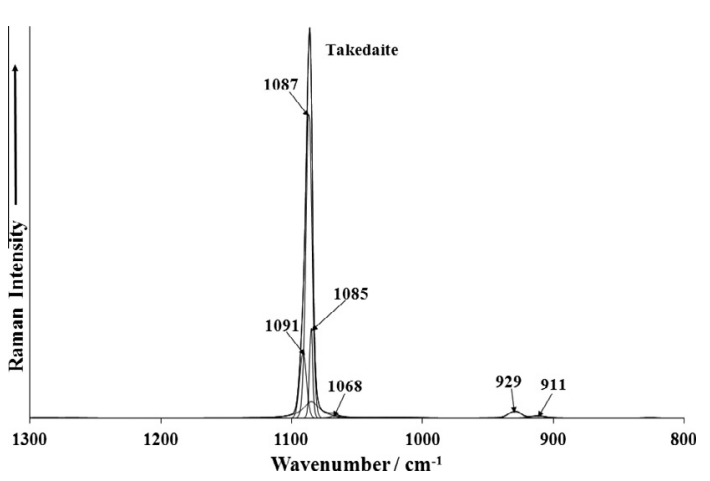

\begin{abstract}
A B S T R A C T
We have studied the mineral takedaite $\mathrm{Ca}_{3}\left(\mathrm{BO}_{3}\right)_{2}$, a borate mineral of calcium using SEM with EDX and vibrational spectroscopy. Chemical analysis shows a homogeneous phase, composed of $\mathrm{Ca}$. Boron was not detected. A very intense Raman band at $1087 \mathrm{~cm}^{-1}$ is assigned to the $\mathrm{BO}$ stretching vibration of $\mathrm{BO}_{3}$ units. Additional Raman bands may be due to isotopic splitting. In the infrared spectrum, bands at $1218 \mathrm{~cm}^{-1}$ and at 1163,1262 and $1295 \mathrm{~cm}^{-1}$ are assigned to the trigonal borate stretching modes. Raman bands at 712 and $715 \mathrm{~cm}^{-1}$ are assigned to the in-plane bending modes of the $\mathrm{BO}_{3}$ units. Vibrational spectroscopy enables aspects of the molecular structure of takedaite to be assessed.
\end{abstract}

(c) 2014 Elsevier B.V. All rights reserved.

\section{Introduction}

The mineral takedaite $\mathrm{Ca}_{3}\left(\mathrm{BO}_{3}\right)_{2}$ is the borate mineral of calcium [1]. It is one of several minerals found at Fuka, Okayama Prefecture, Japan [2]. Takedaite is a rare mineral probably formed by boron-rich fluids reacting between crystalline limestone and gehlenite-spurrite skarns [3,4]. Crystal structure has been refined [5]. The mineral is hexagonal with Point Group: $32 / m$ and Space

\footnotetext{
* Corresponding author. Tel.: +61 73138 2407; fax: +61 731381804 . E-mail address: r.frost@qut.edu.au (R.L. Frost).
}

Group: $R 3 / c$. The unit cell parameters are: $a=8.638 \AA, c=11.85 \AA$, $Z=6 ; V=765.73 \AA^{3}$. The boron isotope ratio $(11 \mathrm{~B} / 10 \mathrm{~B})$ is used to determine the geochemistry of boron minerals including hydroboracite [6-8]. This isotopic ratio may be reflected in the vibrational spectra providing the resolution of the spectrometers is sufficiently high.

Vibrational spectroscopy has been applied to borate glasses [912]. However, the number of vibrational spectroscopic studies of borate minerals is few and far between. The number of vibrational spectroscopic studies of borate minerals is quite few and far between [13-16]. The number of Raman studies of borate minerals 
is also very limited [17,18]. There have been a number of infrared studies of some natural borates [19-22]. Most of these references are not new and there have been no recent studies on the vibrational spectroscopy of natural borates. Ross in Farmer's treatise reported the infrared spectra of several borate minerals [23]. There have been only a few infrared studies of hydroboracite $[19,22,24,25]$ and almost no studies of the Raman spectrum of takedaite [26]. There is some disagreement between researchers as to the position of some selected infrared bands. Moenke [27] and Vlasova and Valyashko [25] show a band at $675 \mathrm{~cm}^{-1}$ which was not observed in the infrared spectrum of Weier [22]. These authors simply reported the infrared data without any assignment of the bands.

Vibrational spectroscopy has proven most useful for the study of borate minerals [28-31]. There are many calcium borate minerals; many contain water and/or hydroxyl units in their structure. There is a vital need to study these calcium borate minerals using vibrational spectroscopy. In the authors view, there is an apparent lack of fundamental knowledge of borate mineral spectroscopy. The authors have made several studies of boron containing minerals [32-35]. The objective of this research is to report the Raman and infrared spectra of takedaite and to relate the spectra to the molecular structure of the mineral. This is the first report of a systematic study of takedaite from Fuka, Japan. It is important to understand the structure of takedaite in order to form nanomaterials based upon its structure. Vibrational spectroscopy enables a better understanding of the structure of takedaite.

\section{Experimental}

\section{Samples description and preparation}

The takedaite sample studied in this work forms part of the collection of the Geology Department of the Federal University of Ouro Preto, Minas Gerais, Brazil, with sample code SAB-096. The sample is from the Fuka mine, located in the Okayama Prefecture, Japan. The studied sample occurs as a massive aggregate of micrometric crystals.

The sample was prepared by using of a stereomicroscope Leica MZ4. The takedaite studied in this work occurs as a pure phase. Scanning electron microscopy (SEM) in the EDS mode was applied to support the mineral characterization.

\section{Scanning electron microscopy (SEM)}

Experiments and analyses involving electron microscopy were performed in the Center of Microscopy of the Universidade Federal

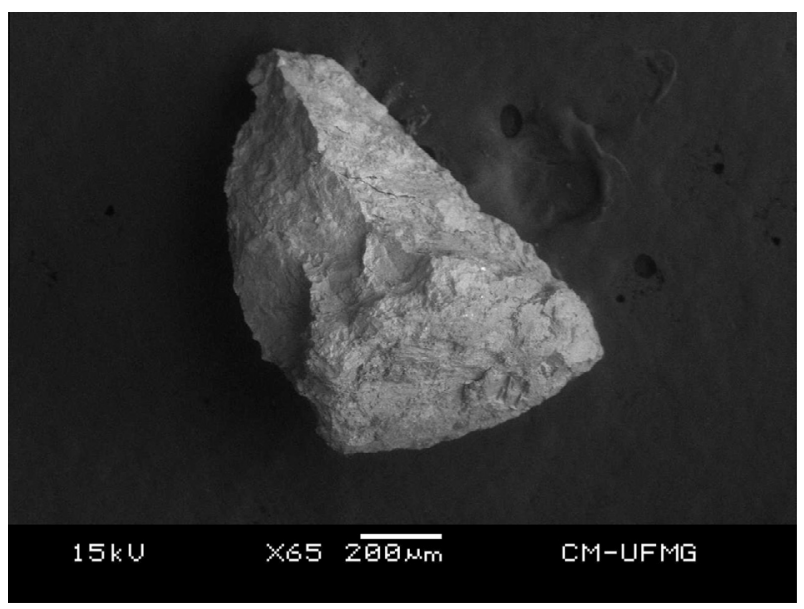

Fig. 1. Backscattered electron image (BSI) of a takedaite fragment up to $2.0 \mathrm{~mm}$ in length. de Minas Gerais, Belo Horizonte, Minas Gerais, Brazil (http:// www.microscopia.ufmg.br).Takedaite crystals were coated with a $5 \mathrm{~nm}$ layer of evaporated carbon. Secondary Electron and Backscattering Electron images were obtained using a JEOL JSM-6360LV equipment. Qualitative and semi-quantitative chemical analyses in the EDS mode were performed with a ThermoNORAN spectrometer model Quest and were applied to support the mineral characterization.

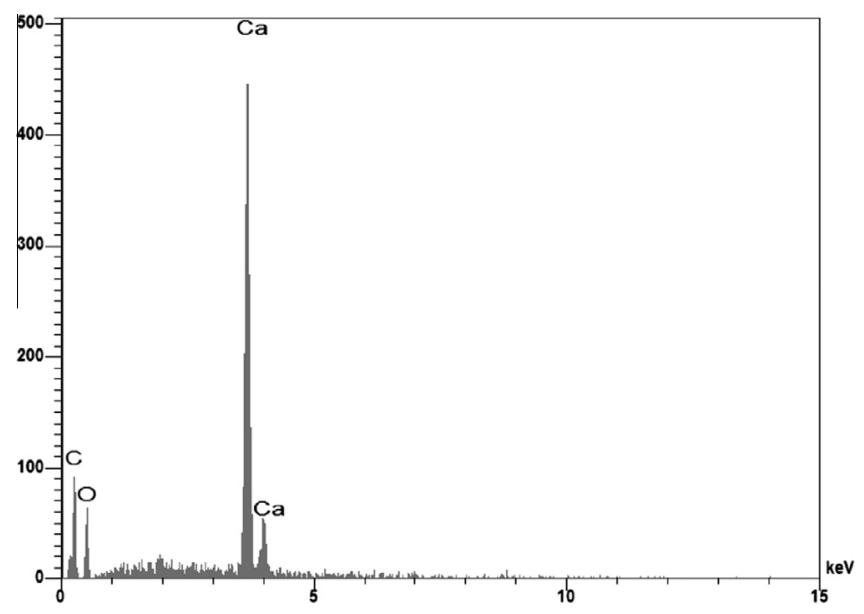

Fig. 2. EDS spectra of takedaite.

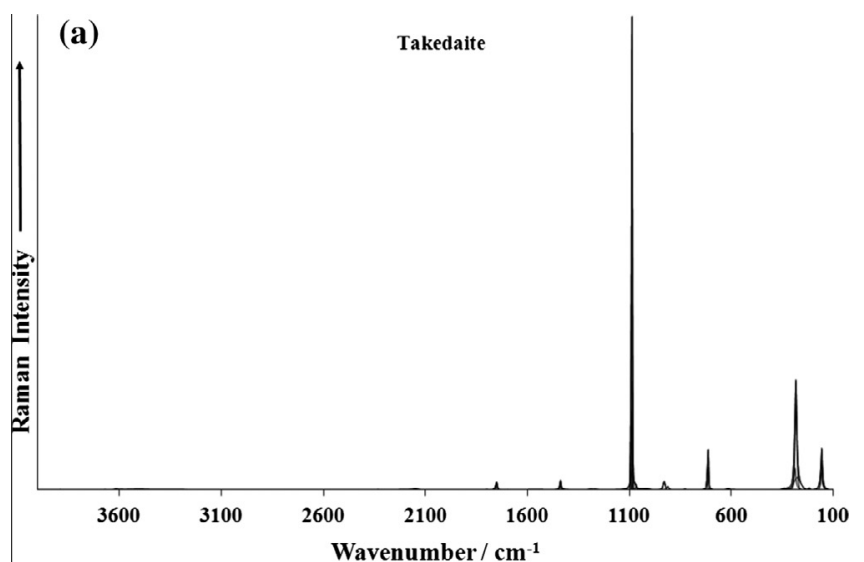

(b)

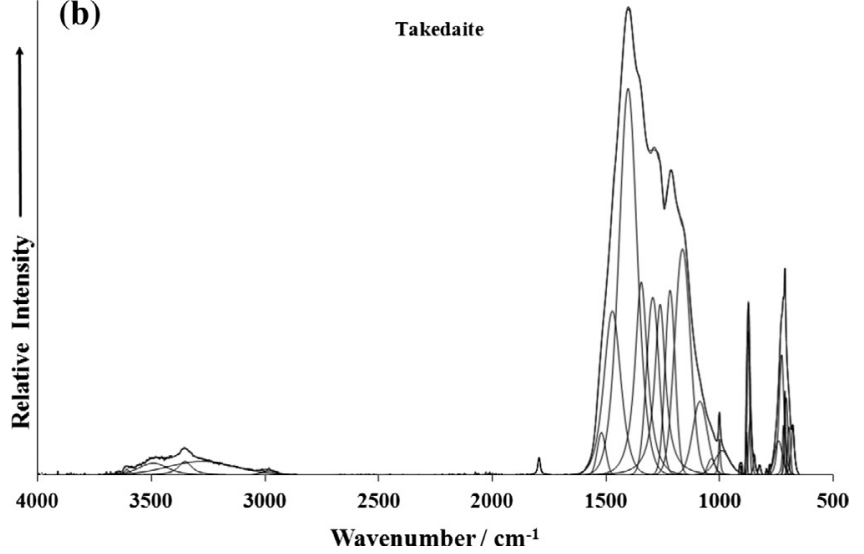

Fig. 3. (a) Raman spectrum of takedaite over the $100-4000 \mathrm{~cm}^{-1}$ spectral range. (b) Infrared spectrum of takedaite over the $500-4000 \mathrm{~cm}^{-1}$ spectral range. 
Raman microprobe spectroscopy

Crystals of takedaite were placed on a polished metal surface on the stage of an Olympus BHSM microscope, which is equipped with $10 \times, 20 \times$, and $50 \times$ objectives. The microscope is part of a Renishaw 1000 Raman microscope system, which also includes a monochromator, a filter system and a CCD detector (1024 pixels). The Raman spectra were excited by a Spectra-Physics model 127 He-Ne laser producing highly polarized light at $633 \mathrm{~nm}$ and collected at a nominal resolution of $2 \mathrm{~cm}^{-1}$ and a precision of $\pm 1 \mathrm{~cm}^{-1}$ in the range between 200 and $4000 \mathrm{~cm}^{-1}$. Repeated acquisitions on the crystals using the highest magnification $(50 \times)$ were accumulated to improve the signal to noise ratio of the spectra. Raman Spectra were calibrated using the $520.5 \mathrm{~cm}^{-1}$ line of a silicon wafer. The Raman spectrum of at least 10 crystals was collected to ensure the consistency of the spectra.

\section{Infrared spectroscopy}

Infrared spectra were obtained using a Nicolet Nexus 870 FTIR spectrometer with a smart endurance single bounce diamond ATR cell. Spectra over the $4000-525 \mathrm{~cm}^{-1}$ range were obtained by the co-addition of 128 scans with a resolution of $4 \mathrm{~cm}^{-1}$ and a mirror velocity of $0.6329 \mathrm{~cm} / \mathrm{s}$. Spectra were co-added to improve the signal to noise ratio.

Spectral manipulation such as baseline correction/adjustment and smoothing were performed using the Spectracalc software package GRAMS (Galactic Industries Corporation, NH, USA). Band component analysis was undertaken using the Jandel 'Peakfit' software package that enabled the type of fitting function to be selected and allows specific parameters to be fixed or varied
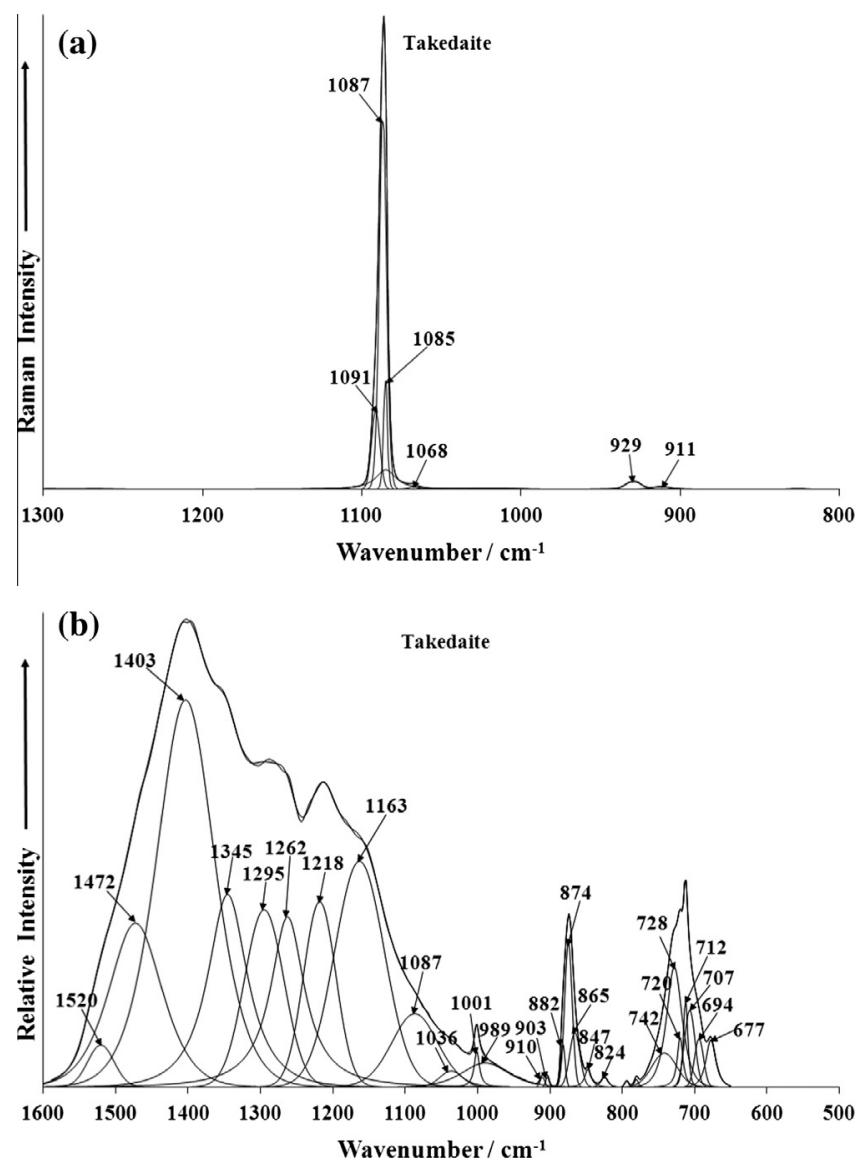

Fig. 4. (a) Raman spectrum of takedaite over the $800-1300 \mathrm{~cm}^{-1}$ spectral range. (b) Infrared spectrum of takedaite over the $500-1600 \mathrm{~cm}^{-1}$ spectral range. accordingly. Band fitting was done using a Lorentzian-Gaussian cross-product function with the minimum number of component bands used for the fitting process. The Gaussian-Lorentzian ratio was maintained at values greater than 0.7 and fitting was undertaken until reproducible results were obtained with squared correlations of $r^{2}$ greater than 0.995 .

\section{Results and discussion}

\section{Chemical characterization}

The SEM image of the mineral sample takedaite studied in this work is shown in Fig. 1. The image shows a takedaite microcrystaline aggregate. Qualitative chemical analysis shows a homogeneous phase, composed of Ca. Carbon was also observed and occurs due to $C$ coating (Fig. 2). Boron was not detected as the atomic number is low.

\section{Vibrational spectroscopy}

The Raman spectrum of takedaite over the $100-4000 \mathrm{~cm}^{-1}$ spectral range is shown in Fig. 3a. This spectrum shows the position and intensity of the Raman bands. The observed bands are very sharp. No intensity above $1700 \mathrm{~cm}^{-1}$ is observed. The Raman spectrum may be subdivided into sections based upon the type of vibration being analyzed. The infrared spectrum of takedaite over the $500-4000 \mathrm{~cm}^{-1}$ spectral range is illustrated in Fig. 3b. In comparison with the Raman spectrum the bands are broad and overlap. Now in the infrared spectrum, some intensity is observed in the $3000-4000 \mathrm{~cm}^{-1}$ spectral range.
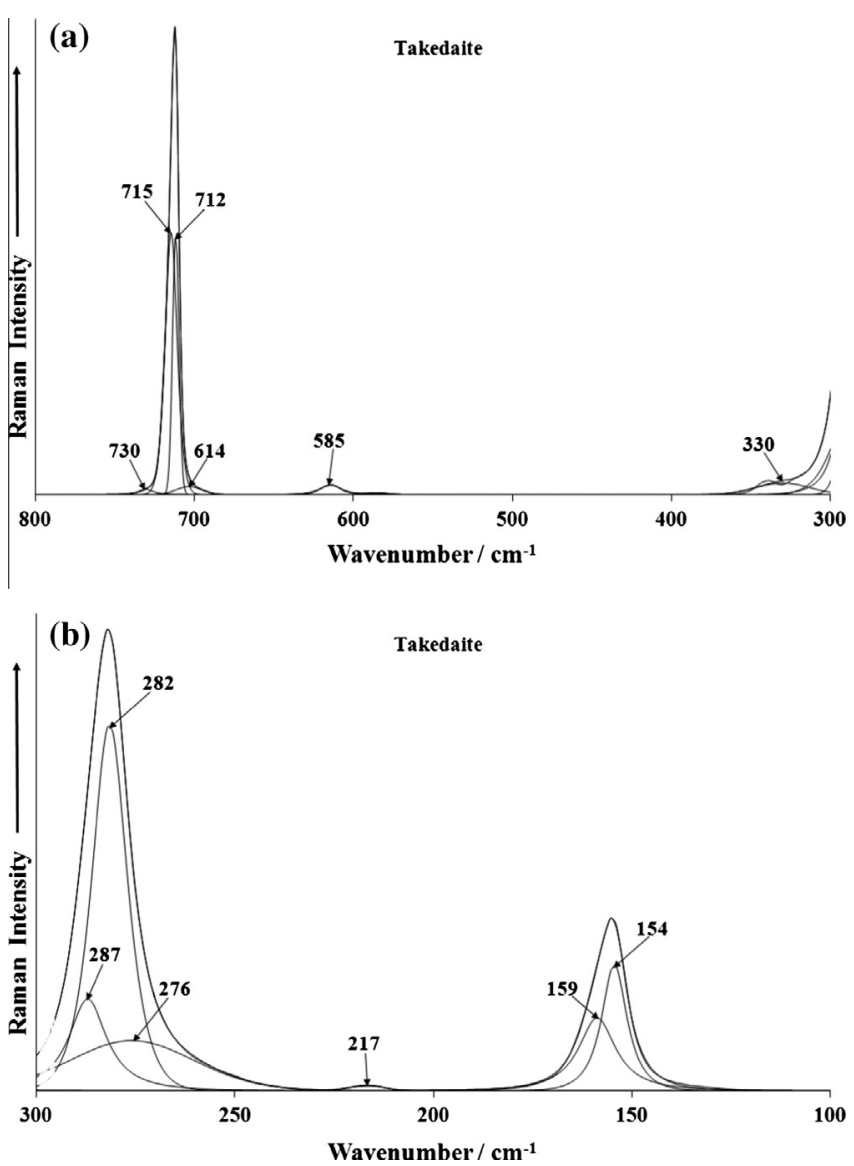

Fig. 5. (a) Raman spectrum of takedaite over the $300-800 \mathrm{~cm}^{-1}$ spectral range. (b) Raman spectrum of takedaite over the $100-300 \mathrm{~cm}^{-1}$ spectral range. 
The Raman spectrum over the $800-1300 \mathrm{~cm}^{-1}$ spectral range is reported in Fig. 4a. The spectrum is dominated by an intense Raman band at $1087 \mathrm{~cm}^{-1}$. This band is assigned to the BO stretching vibration of $\mathrm{BO}_{3}$ units. Some low intensity shoulder bands are noted at 1085 and $1091 \mathrm{~cm}^{-1}$. Iliev et al. determined the Raman spectrum of a synthetic cobalt boracite [36]. The symmetry species of some vibrational modes were determined. Iliev et al. [37] used Raman imaging to show the ferroelectric properties of boracite type compounds. These workers [37] showed that boracites exhibit a sequence of transitions from the high temperature paraelectric cubic phase to ferroelectric orthorhombic, monoclinic, trigonal phases, and finally to a monoclinic phase at low temperatures where both ferroelectric and magnetic orders coexist. Kim and Somoano determined the improper ferroelectric transition using Raman spectroscopy [38].

In contrast, the infrared spectrum of boracite (Fig. 4b) shows complexity with many overlapping bands, making band attribution difficult. The intense infrared band at $1218 \mathrm{~cm}^{-1}$ with shoulders at 1163, 1262 and $1295 \mathrm{~cm}^{-1}$ is assigned to the trigonal borate stretching modes. The overlapping infrared bands are the infrared BO antisymmetric stretching vibrations. According to Ross [23] (page 220 of this reference), bands between 1300 and $1500 \mathrm{~cm}^{-1}$ are due to the antisymmetric stretching modes of trigonal boron. This is perhaps confirmed by the intensity of the infrared bands in the $1300-1500 \mathrm{~cm}^{-1}$ region. The series of bands from 600 through to $800 \mathrm{~cm}^{-1}$ are related to trigonal borate bending modes. Infrared bands are observed at $677,694,707,712,728$, and $742 \mathrm{~cm}^{-1}$. The infrared bands at 1345,1403 and $1472 \mathrm{~cm}^{-1}$ are related to the out-of-plane OBO bending modes.

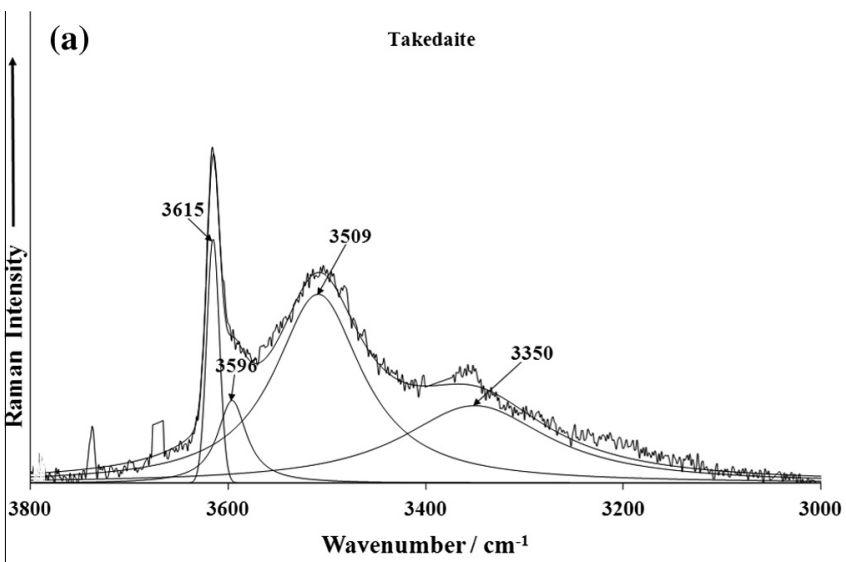

(b)

Takedaite

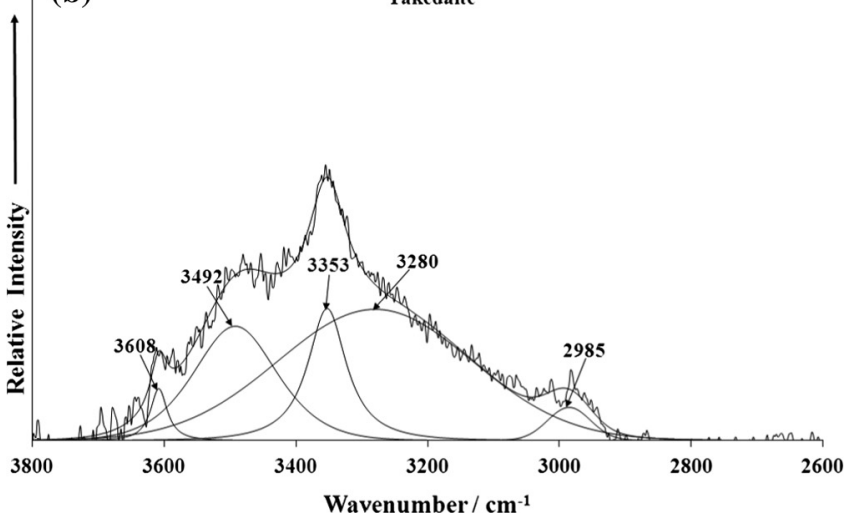

Fig. 6. (a) Raman spectrum of takedaite over the $3000-3800 \mathrm{~cm}^{-1}$ spectral range. (b) Infrared spectrum of takedaite over the $2600-3800 \mathrm{~cm}^{-1}$ spectral range.
The Raman spectrum of takedaite over the $300-800 \mathrm{~cm}^{-1} \mathrm{spec}-$ tral range is shown in Fig. 5a. The Raman spectrum of takedaite over the $100-300 \mathrm{~cm}^{-1}$ spectral range is shown in Fig. 5b. Intense Raman bands are observed at 712 and $715 \mathrm{~cm}^{-1}$ and are assigned to the in-plane bending modes of the $\mathrm{BO}_{3}$ units. A low intensity Raman band is found at $585 \mathrm{~cm}^{-1}$. A very intense Raman band is observed at $282 \mathrm{~cm}^{-1}$ with shoulders at 276 and $287 \mathrm{~cm}^{-1}$. These bands are attributed to $\mathrm{CaO}$ stretching vibrations. The Raman bands at 154 and $159 \mathrm{~cm}^{-1}$ are simply described as lattice vibrations.

The mineral takedaite has the formula $\mathrm{Ca}_{3}\left(\mathrm{BO}_{3}\right)_{2}$ and as such contains no water or hydroxyl groups. The Raman spectrum of takedaite over the $3000-3800 \mathrm{~cm}^{-1}$ spectral range is provided in Fig. 6a. The spectrum is very noisy. Nevertheless, Raman bands may be resolved at 3350,3509 and $3615 \mathrm{~cm}^{-1}$. The first two bands are due to the stretching vibrations of water, whilst the Raman band at $3615 \mathrm{~cm}^{-1}$ is due to the stretching vibrations of $\mathrm{OH}$ units. It is suggested that we are picking up the spectrum of some other mineral. A number of possible minerals may be nominated namely colemanite, fabianite, gowerite and priceite. The infrared spectrum over the $2600-3800 \mathrm{~cm}^{-1}$ spectral range is given in Fig. 6b. As for the Raman spectrum, the spectrum is very noisy and suffers from a lack of signal. Infrared bands may be resolved at 3280, 3353, 3492 and $3608 \mathrm{~cm}^{-1}$. The infrared spectrum bears a strong resemblance to the Raman spectrum.

The Raman spectrum of takedaite over the $1300-2300 \mathrm{~cm}^{-1}$ spectral region is shown in Fig. 7a. Two intense Raman bands are found at 1436 and $1439 \mathrm{~cm}^{-1}$. These bands are assigned to the antisymmetric stretching vibrations of trigonal boron. These bands
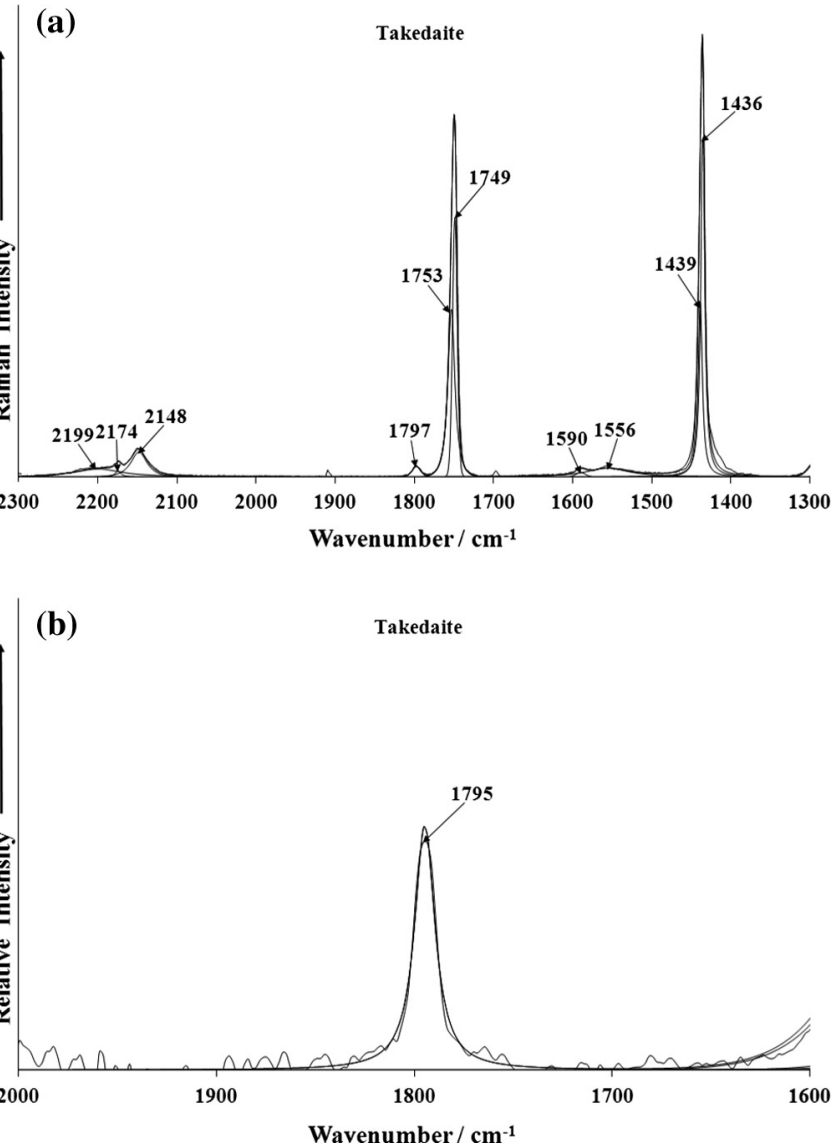

Fig. 7. (a) Raman spectrum of takedaite over the $1300-2300 \mathrm{~cm}^{-1}$ spectral range. (b) Infrared spectrum of takedaite over the $1300-1800 \mathrm{~cm}^{-1}$ spectral range. 
may be due to isotopic splitting. These bands are assigned to the antisymmetric stretching vibrations of trigonal boron [23] (please see Table 11 .VIII of this reference). Two low intensity Raman bands are noted at 1556 and $1590 \mathrm{~cm}^{-1}$. Two intense Raman bands are observed at 1749 and $1753 \mathrm{~cm}^{-1}$ with a shoulder band at $1797 \mathrm{~cm}^{-1}$. These bands are also attributed to the antisymmetric stretching vibrations of trigonal boron [23]. In the case of the infrared spectrum (Fig. 7b), only one infrared band at $1795 \mathrm{~cm}^{-1}$ is observed. No water bending modes were found. Low intensity Raman bands at 2148, 2174 and $2199 \mathrm{~cm}^{-1}$ are observed. These bands may be associated with overtone or combination bands.

\section{Conclusions}

There are many borate minerals. Most are either hydrate or contain hydroxyl groups or both. Many of these minerals have never been analyzed using vibrational spectroscopy. In this instance, we have studied the anhydrous borate mineral takedaite. Chemical analysis shows a homogeneous phase, composed by Ca. Vibrational spectroscopy proves the absence of either water or hydroxyl units in the structure. The spectra are characterized by a trigonal borate with intense Raman bands at 712, 715 and $1087 \mathrm{~cm}^{-1}$. Raman spectroscopy allows the possibility of distinguishing takedaite from the other boron containing calcium minerals.

\section{Acknowledgements}

The financial and infra-structure support of the Discipline of Nanotechnology and Molecular Science, Science and Engineering Faculty of the Queensland University of Technology, is gratefully acknowledged. The Australian Research Council (ARC) is thanked for funding the instrumentation. The authors would like to acknowledge the Center of Microscopy at the Universidade Federal de Minas Gerais (http://www.microscopia.ufmg.br) for providing the equipment and technical support for experiments involving electron microscopy.

\section{References}

[1] I. Kusachi, C. Henmi, S. Kobayashi, Min. Mag. 59 (1995) 549-552.

[2] I. Kusachi, S. Kobayashi, C. Henmi, Y. Takechi, Kobutsugaku Zasshi 28 (1999) 41-46.

[3] S.M. Aleksandrov, Geokhimiya (2003) 492-512.

[4] S.M. Aleksandrov, M.A. Troneva, Geochem. Int. 50 (2012) 885-898.

[5] A. Vegas, F.H. Cano, S. Garcia-Blanco, Acta Crystall. B31 (1975) 1416-1419.

[6] S.V. Malinko, A.E. Lisitsyn, L.V. Sumin, Doklady Akad. 267 (1982) 453-456.

[7] S.V. Malinko, A.E. Lisitsyn, L.V. Sumin, Sovetskaya Geol. (1987) 89-97.

[8] M.R. Palmer, C. Helvaci, Geochim. Cosmochim. Acta 61 (1997) 3161-3169.

[9] I. Ardelean, S. Cora, J. Mater. Sci. 19 (2008) 584-588.

[10] I. Ardelean, S. Cora, J. Optoelectron. Adv. Mater. 12 (2010) 239-243.

[11] I. Ardelean, L. Griguta, J. Optoelectron. Adv. Mater. 9 (2007) 2068-2070.

[12] I. Ardelean, V. Timar, J. Optoelectron. Adv. Mater. 10 (2008) 246-250.

[13] M. Mir, J. Janczak, Y.P. Mascarenhas, J. Appl. Crystallogr. 39 (2006) 42-45.

[14] I. Mitov, Z. Cherkezova-Zheleva, V. Mitrov, J. Balkan Trib. Assoc. 4 (1998) 191200.

[15] A.S. Povarennykh, E.I. Nefedov, Geol. Zh. 31 (1971) 13-27.

[16] V.S. Suknev, E.N. Diman, Zh. Prikl. Spektrosk. 10 (1969) 326-328.

[17] V.F. Ross, J.O. Edwards, Chem. Boron its Compd., 1967, pp. 15-207.

[18] R.L. Frost, J. Raman Spectrosc. 42 (2011) 540-543.

[19] M.V. Akhmanova, Zh. Strukt. Khim. 3 (1962) 28-34.

[20] D.A. Long, R.T. Bailey, Spectrochim. Acta 19 (1963) 1607-1610.

[21] A. Vasko, I. Srb, Czech. J. Phys. 17 (1967) 1110-1123.

[22] C.E. Weir, J. Res. Nat. Bur. Stand. A70 (1966) 153-164.

[23] V.C. Farmer, Mineralogical Society Monograph 4: The Infrared Spectra of Minerals, Mineralogical society, London, 1974.

[24] M.G. Valyashko, E.V. Vlasova, Jena Rev. 14 (1969) 3-11.

[25] E.V. Vlasova, M.G. Valyashko, Zh. Neorgan. Khim. 11 (1966) 1539-1547.

[26] X. Xie, F. Zha, Kuangwu Xuebao 13 (1993) 130-136.

[27] H. Moenke, Silikattechnik 13 (1962) 287-288.

[28] R.L. Frost, Y. Xi, R. Scholz, F.M. Belotti, M. Candido Filho, J. Mol. Struct. 1037 (2013) 23-28.

[29] R.L. Frost, R. Scholz, A. Lopez, Y. Xi, L.M. Graca, J. Mol. Struct. 1059 (2014) 2026.

[30] R.L. Frost, A. Lopez, Y. Xi, R.M.F. Lima, R. Scholz, A. Granja, Spectrochim. Acta A116 (2013) 160-164.

[31] R.L. Frost, Y. Xi, R. Scholz, Spectrochim. Acta A96 (2012) 946-951.

[32] J.T. Kloprogge, R.L. Frost, Appl. Spectrosc. 53 (1999) 356-364.

[33] R.L. Frost, Y. Xi, Spectrochim. Acta A96 (2012) 831-836.

[34] R.L. Frost, Y. Xi, Spectrochim. Acta A 96 (2012) 89-94.

[35] R.L. Frost, Y. Xi, Spectrochim. Acta A96 (2012) 611-616.

[36] M.N. Iliev, V.G. Hadjiev, M.E. Mendoza, J. Pascual, Phys. Rev. B76 (2007). 214112/214111-214112/214115.

[37] M.N. Iliev, V.G. Hadjiev, J. Iniguez, J. Pascual, Acta Phys. Pol. A116 (2009) 1924.

[38] Q. Kim, R.B. Somoano, Ferroelectrics 36 (1981) 431-434. 